\title{
A Study On Effectiveness Of Competency Mapping Through Training And Development
}

\author{
Dr. Saikumari $V^{1}$, Ms. Sunitha $V^{2}$, Kirthika S V ${ }^{3}$, Jayakrishna A $\mathbf{R}^{4}$, Lokeshwaran $\mathrm{K}^{5}$ \\ ${ }^{1}$ Professor, Head of the Department \\ Department of Management Studies \\ SRM Easwari Engineering College \\ Ramapuram, Chennai. \\ dr.kumaris@gmail.com \\ ${ }^{2}$ Professor \\ Department of Management Studies \\ SRM Easwari Engineering College \\ Ramapuram, Chennai. \\ sunithaparthu13@gmail.com \\ ${ }^{3}$ Research Scholar \\ Department of Management Studies \\ SRM Easwari Engineering College \\ Ramapuram, Chennai \\ kirthika1999vasu@gmail.com \\ ${ }^{4}$ Research Scholar \\ Department of Management Studies \\ SRM Easwari Engineering College \\ Ramapuram, Chennai \\ krishravirajulu@gmail.com \\ ${ }^{5}$ Research Scholar \\ Department of Management Studies \\ SRM Easwari Engineering College \\ lokshield@gmail.com
}

Article History: Received: 10 January 2021; Revised: 12 February 2021; Accepted: 27 March 2021; Published online: 10 May 2021

\begin{abstract}
-
In today's corporate world, many companies and organization are increasingly focusing on human capital as a competitive advantage in rapidly changing environment. Many successful companies realize that their employees are their greatest asset. Therefore, companies are increasingly investing in educating their own employees so that they can grow and change within the company and make it more profitable.

The range of training opportunities varies considerable from company to company so, when researching potential employers, it is important for job seekers who care about this to investigate the level and type of training provided to employees. After employees have been selected for various positions in an organization, training them for specific tasks to which they have been assigned assumes greater importance.

This study suggests the organization to implement more modern training methodologies, then to provide practical training to the employees and to provide specific learning assignments or projects for participants to improve on their competency gap.
\end{abstract}

KEY WORDS: Competencies; Competency Mapping; Learning and development; Organisational study Training and development; Individual development and desired outcomes. 


\section{INTRODUCTION}

Competency development is making its entry into a lot of organizations nowadays and is becoming a crucial strategic management tool in today's work environment. In today's corporate world, evaluation of competency plays a vital role. Many companies started investing on their own staff resources and training to retain them. Competency Development Framework (CDF) is a structured process to improve and cultivate good work skills for employees across all levels in a uniform manner.

Competency Mapping is a process of identifying key competencies required to perform successfully in a given job or role /a set of tasks at given point of time. Competencies are enhanced through training and job rotation. Competency based recruitment will result proper selection as per criteria found from mapping and assessment, employee will know his job and can perform his more independently and employee morale will be boost up.

\section{A. BENEFITS OF COMPETENCY DEVELOPMENT:}

- It helps to meet business results by capability building of employees.

- It sets performance expectations

- It establishes common criteria for hiring, training, rewarding people with right capabilities to help company gain competitive advantage.

- It helps to identify gaps between current people capabilities and future requirements

- It facilitates organizational change and build desired culture

\section{PROBLEM STATEMENT}

- To identify the effectiveness of competency assessment and Individual development plan towards employees in the organisation.

- To identify the satisfaction of employees in filling the gap between the required proficiency level (RPL) and current proficiency level (CPL).

- To identify whether the areas for improvement matrix (AFI = RPL-CPL) is correctly identified for each employees.

- To measure how effectively training is given to all the employees in the organization.

\section{NEED AND SCOPE OF THE STUDY}

- To provide employees with clear direction on how they can contribute to the organization.

- To reinforces behaviors that are consistent with organization's mission and goals.

- To provide employees with a roadmap for building strengths and closing development gaps.

- To improve consistency in recruiting and selection, training, performance management and succession planning

- To facilitate organizational change and build desired culture.

\section{OBJECTIVES}

\section{PRIMARY OBJECTIVE:}

To study the various competency skill possessed by the employees based on their work level in the organization.

\section{SECONDARY OBJECTIVE:}

- To study functional and behavioral capability of individual employees and to identify the competent work force.

- To measure the effectiveness of training given on functional and behavioral competencies.

- To suggest the training and development programs to improve competency skills of employees. 


\section{REVIEW OF LITERATURE}

D. Mohanakumari and R. Magesh (2017) their idea is to test the competency level of employees and to find their satisfaction level towards it. They have concluded that the employees are satisfied with the present competency skill training facility provided by the organisation.

Ajay Koushik (2014) concluded that every firm should have well defined roles and list of competencies required to perform each role effectively. This information not only helps to identify individuals who have the matching skills for doing the work but also the skills that will enhance the successful performance of the work. HR professional have realized the importance of competency mapping and they believe that, the future belongs to competent people and competency based organizations.

Dr. Masood Ikram, Dr. Mahalakshmi, M. J. Abirami, Dr. Swaminathan (2019) concluded that there is a gap in competency. Skill level was found to be comparatively lesser than Knowledge and attitude. This revealed the need for Continuous Education through training which will facilitate knowledge enrichment and skill development.

Dr. Anand B. Dadas concluded that the competency mapping is useful for managers in identifying performance level, performance standards, good communication, improving relationship between employer and employee and reduce the career related issues. Thus Competency Mapping and Competency Development are essential practices and new approach towards globalization.

Ms. Gayatri Panda, Dr. Sumita Mishra their motive of the study is to know the impact of training in top level, middle level and lower level in an organizational setting and they found out the linkage between existing competencies and training need identification. Hence they concluded that employee competencies have close relationship with training need identification. They also said that the design of training should be based on their employees existing competencies and bridge the gap between the future requirements.

M. Jyothi Sheeba, Prabu B Christopher, Through their study they proved that Training and Development plays a vital role in improving the performance of the employees through inculcating the innovative work behaviors which helps in accomplishing non-routine cognitive jobs effectively and innovatively.

\section{RESEARCH METHODOLOGY}

Research is an art of scientific investigation. The advanced learner's dictionaries of current English lay down the meaning of research as, "a careful investigation (or) inquiry especially through search for new facts in any branch of knowledge".

Methodology is a way to systematically solve the research problem.

\section{RESEARCH DESIGN:}

- The researcher used descriptive research design for this study.

SAMPLING METHOD:

- Simple random sampling method was adopted for the study.

RESEARCH INSTRUMENT:

- The research instrument used in the study is a Structured Questionnaire.

\section{DATA COLLECTION METHOD:}

The main source of information for this study is based on the data collection. Data collected are both primary and secondary in nature.

- Primary data - Primary data have been directly collected from the employees of Tube investments of India by survey method through Structured questionnaire. 
- Secondary data - Secondary data was collected from official website of the company, various published books, various journal articles and company records.

\section{DATA ANALYSIS AND INTERPRETATION:}

\section{INFERENTIAL ANALYSIS:}

- Spearman Correlation analysis between faculty effectiveness and coverage, content of the training.

- Spearman correlation is simply a Pearson correlation computed on ranks instead of data values or categories. Spearman correlations are always between -1 and +1 .

\section{HYPOTHESIS TESTING:}

- Null Hypothesis $\left[\mathrm{H}_{\mathrm{a} 0}\right]$ : There is no significant relationship between Faculty effectiveness, Content and coverage of the training.

Alternate Hypothesis $\left[\mathrm{H}_{\mathrm{a1}}\right]$ : There is significant relationship between Faculty effectiveness, Content and coverage of the training.

- Null Hypothesis $\left[\mathrm{H}_{\mathrm{b} 0}\right]$ : There is no significant association between relevancy of the training provided to the employees and its application.

Alternate Hypothesis [ $\left.\mathrm{H}_{\mathrm{b} 1}\right]$ : There is a significant association between relevancy of the training provided to the employees and its application.

\section{TRAINING 1 - CHANGE MANAGEMENT (BEHAVIORAL)}

Change management is willing to voice his/her opinions against superiors and leaders within the team and challenges the status quo at work. It is inclined towards implementing change and proactively encourages others to do the same.

\begin{tabular}{|l|l|}
\hline STATEMENTS & $\begin{array}{l}\text { Content and Coverage Vs } \\
\text { Faculty effectiveness }\end{array}$ \\
\hline $\begin{array}{l}\text { Spearman Correlation } \\
\left.\text { Coefficient ( } \mathrm{r}_{\mathrm{s}}\right)\end{array}$ & $\mathbf{1 . 0 0}$ \\
\hline $\begin{array}{l}\text { Statistically Significant } \\
(\mathrm{p})\end{array}$ & $\mathbf{0 . 6 3 3}$ \\
\hline
\end{tabular}

\section{INFERENCE:}

A Spearman's rank order correlation was run to determine the relationship between Content and coverage of the training and Faculty effectiveness. There was a Strong and positive correlation between Content, Coverage and faculty effectiveness, which was statistically significant $\left(\mathrm{r}_{\mathrm{s}}=1.00, \mathrm{p}=0.633\right)$.

\section{CONCLUSION:}

- Null hypothesis is rejected and there is significant relationship between the content and coverage of the training title and faculty effectiveness. Thus we accept alternate hypothesis.

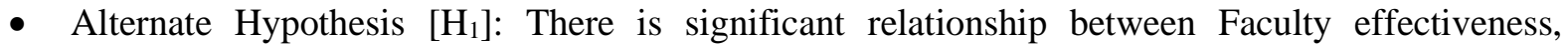
Content and coverage of the training. 


\section{TRAINING 2 - FINANCE FOR NON-FINANCE (FUNCTIONAL)}

\begin{tabular}{|l|l|}
\hline STATEMENTS & $\begin{array}{l}\text { Relevancy of the training } \\
\text { Vs its application }\end{array}$ \\
\hline $\begin{array}{l}\text { Spearman } \\
\text { Correlation } \\
\text { Coefficient }\left(\mathrm{r}_{\mathrm{s}}\right)\end{array}$ & $\mathbf{1 . 0 0}$ \\
\hline $\begin{array}{l}\text { Statistically } \\
\text { Significant }(\mathrm{p})\end{array}$ & $\mathbf{0 . 1 7 0}$ \\
\hline
\end{tabular}

\section{INFERENCE:}

A Spearman's rank order correlation was run to determine the relationship between relevancy of the training provided to the employees and its application. There was a Strong, positive correlation between relevancy of the training provided to the employees and its application, which was statistically significant $\left(\mathrm{r}_{\mathrm{s}}=1.00, \mathrm{p}=0.170\right)$.

\section{CONCLUSION:}

- Null hypothesis is rejected and there is significant relationship between relevancy of the training provided to the employees and its application. Thus we accept alternate hypothesis.

- Alternate Hypothesis $\left[\mathrm{H}_{1}\right]$ : There is a significant association between relevancy of the training provided to the employees and its application.

\section{FINDINGS AND SUGGESTIONS}

- It is found that majority of the respondents belong to the work level 1 (Individual contributor) and the least belong to work level 4 (First time leader).

- It is found that when we compare the behavioral competency training and functional competency training, employees are more satisfied with the training given on behavioral competencies.

- From the secondary data analysis it is observed that employees are highly satisfied with the competencies framed to their level and the training given to them to fill their competency gap.

- It is observed that employees believe that these competencies will surely help them to achieve their goal along with the objectives of the organization.

- They can concentrate more on developing the hands on practical sessions than theoretical classroom sessions or Virtual Training sessions.

- As per the request of the employees who attended the training programs, company need to share the Power point presentations, case studies etc., which are discussed during the training.

- Specific learning assignments or projects should be allowed for participants to improve on their competency gaps.

- It is suggested that organization can provide more Simulation training within Organization which will help to improve the leadership skills of the employees.

- Recruitment and selection processes must be carried out by considering competency of the individuals.

- The company shall organise career development programme frequently at regular intervals to improve the efficiency of the employees. 


\section{CONCLUSION}

The present study has been attempted to get an idea regarding the competency level of the employees and their satisfaction towards the training. It is found that the employees are satisfied with the present competency skill training facility provided by the organization. The competency level of the employees can be increased if more training is provided. Organization can conduct more Simulation training to improve the leadership skills of the employees. Thus Competency Mapping is essential practice and new approach towards globalization.

\section{REFERENCES:}

1) https://www.worldwidejournals.com/paripex/recent_issues_pdf/2015/January/January_2015_142 1670807_61.pdf

2) https://www.researchgate.net/publication/328293983_Impact_of_Competency_Based_Training_Nee d_Assessment_on_Individual_Performance_A_Study_on_Employees_of_Essel_Mining_Industries

3) https://www.researchgate.net/publication/281585786_COMPETENCY_DEVELOPMENT_INTE GRATION_AND_APPLICATION

4) https://www.ncbi.nlm.nih.gov/pmc/articles/PMC7419574/

5) https://hr.un.org/sites/hr.un.org/files/UN-Competency-Development-A-practical-guide_0_1.pdf

6) https://corporatefinanceinstitute.com/resources/careers/soft-skills/employee-training-anddevelopment/

https://www.researchgate.net/publication/271845562_Competence_development_in_the_workplace_Con cepts_strategies_and_effects 